\title{
The Stigma of Migraine
}

\section{William B. Young ${ }^{1 *}$, Jung E. Park ${ }^{1}$, Iris X. Tian ${ }^{1}$, Joanna Kempner ${ }^{2}$}

1 Department of Neurology, Thomas Jefferson University, Philadelphia, Pennsylvania, United States of America, 2 Department of Sociology, Rutgers University, New Brunswick, New Jersey, United States of America

\begin{abstract}
Background: People who have a disease often experience stigma, a socially and culturally embedded process through which individuals experience stereotyping, devaluation, and discrimination. Stigma has great impact on quality of life, behavior, and life chances. We do not know whether or not migraine is stigmatizing.

Methods: We studied 123 episodic migraine patients, 123 chronic migraine patients, and 62 epilepsy patients in a clinical setting to investigate the extent to which stigma attaches to migraine, using epilepsy as a comparison. We used the stigma scale for chronic illness, a 24-item questionnaire suitable for studying chronic neurologic diseases, and various disease impact measures.

Results: Patients with chronic migraine had higher scores $(54.0 \pm 20.2)$ on the stigma scale for chronic illness than either episodic migraine $(41.7 \pm 14.8)$ or epilepsy patients $(44.6 \pm 16.3)(p<0.001)$. Subjects with migraine reported greater inability to work than epilepsy subjects. Stigma correlated most strongly with the mental component score of the short form of the medical outcomes health survey (SF-12), then with ability to work and migraine disability score for chronic and episodic migraine and the Liverpool impact on epilepsy scale for epilepsy. Analysis of covariance showed adjusted scores for the stigma scale for chronic illness were similar for chronic migraine (49.3; 95\% confidence interval, 46.2 to 52.4) and epilepsy (46.5; $95 \%$ confidence interval, 41.6 to 51.6$)$, and lower for episodic migraine (43.7; $95 \%$ confidence interval, 40.9 to 46.6$)$. Ability to work was the strongest predictor of stigma as measured by the stigma scale for chronic illness.
\end{abstract}

Conclusion: In our model, adjusted stigma was similar for chronic migraine and epilepsy, which were greater than for episodic migraine. Stigma correlated most strongly with inability to work, and was greater for chronic migraine than epilepsy or episodic migraine because chronic migraine patients had less ability to work.

Citation: Young WB, Park JE, Tian IX, Kempner J (2013) The Stigma of Migraine. PLoS ONE 8(1): e54074. doi:10.1371/journal.pone.0054074

Editor: Pierre-Marie Preux, Institute of Neuroepidemiology and Tropical Neurology, France

Received July 20, 2012; Accepted December 6, 2012; Published January 16, 2013

Copyright: (c) 2013 Young et al. This is an open-access article distributed under the terms of the Creative Commons Attribution License, which permits unrestricted use, distribution, and reproduction in any medium, provided the original author and source are credited.

Funding: The authors have no support or funding to report.

Competing Interests: The authors have declared that no competing interests exist.

*E-mail: William.B.Young@jefferson.edu

\section{Introduction}

Stigma is an established construct in the social sciences that describes a characteristic, trait, or diagnosis that discredits individuals and elicits prejudice, discrimination, and loss of status. Goffman characterized stigma as a process that spoils the identity of the stigmatized individual [1]. Many diseases, such as HIV, depression, and epilepsy, are known to be stigmatizing and result in disruption of social relationships, decreased quality of life, and loss of employment [2-4]. While being stigmatized is in itself a negative consequence of disease, it also has health implications, because it affects the way individuals experiencing stigma seek and access medical care, and because the lack of social belonging is stressful and incurs negative health outcomes [5-7].

Stigma attaches to disease to varying degrees and in various ways. Stigma can be "enacted," as when individuals actually experience discrimination, for example, through the loss of a social relationship or employment. Stigma may also be "internalized" or perceived, which refers to individual's own feelings about their condition, including anticipation about how others might react to it [8]. Subjective experiences of stigma can be as damaging to health as acts of discrimination and the actual loss of social relationships [9]. Although many claim that migraine is stigma- tizing, to date there has been only one study on stigma in people with migraine [10]. In our study we measure how much stigma migraine patients experience in comparison to epilepsy patients-a group that has been studied extensively [11].

\section{Methods}

\section{Study Population}

Between October 2009 and July 2011, we recruited patients with migraine or epilepsy from the Jefferson Headache Center and the Jefferson Comprehensive Epilepsy Center in Philadelphia, Pennsylvania. Questionnaires were administered in an office setting. Inclusion criteria were subjects between the ages of 1865, who had migraine or epilepsy diagnosed by a specialist. Exclusion criteria were inability to give accurate responses and a diagnosis of epilepsy and severe episodic migraine (EM) or chronic migraine $(\mathbf{G M})$. Migraine is a primary headache disorder with attacks lasting 4 to 72 hours untreated and at least two of the following features: severe pain, unilaterality, throbbing, or exacerbation with activity; and one of the following features: nausea or light and sound sensitivity. The migraine type was determined by an attending physician who was board certified in 
headache medicine, following criteria set forth in the International Classification of Headache Disorders [12]. If the number of headache days per month is greater than 14, and eight of these headache days met criteria for migraine (or would if not treated), then the person had CM. If the number of headache days per month is 14 or less, then the person had EM.

The institutional review board at Thomas Jefferson University Hospital reviewed and approved this study, and written informed consent was obtained from each participant.

\section{Questionnaire Administration}

Both migraine and epilepsy patients completed a demographic questionnaire, the stigma scale for chronic illness (SSCI), and the short form of the medical outcomes health survey (SF-12). They also completed a rankable series of questions on their actual or potential (if they should try to get a job) disability. Migraine patients completed the migraine disability score (MIDAS) and answered a rankable series of questions on the degree of resting necessitated by their headaches, and epilepsy patients completed the Liverpool impact of epilepsy scale.

\section{Stigma Scale for Chronic Illness (SSCl)}

The SSCI is a 24-item questionnaire that quantifies the degree and impact of stigma in patients with chronic illnesses. Thirteen items measure "self/internalized stigma," asking, for example, whether the subject feels a sense of shame or anxiety about their condition (SSCI-I) and 11 measure "enacted stigma," asking, for example, about instances of actual discrimination (SSCI-E) $[13,14]$.

\section{SF-12 Health Survey}

The SF-12 is a subset of the SF-36 quality-of-life questionnaire that is used for patient-based assessments of physical and mental health.

\section{MIDAS}

The MIDAS is a brief questionnaire that is used to quantify the disability of migraine over a 3-month period. The number of days the patient had migraine in the last 90 days and the average headache severity are also assessed.

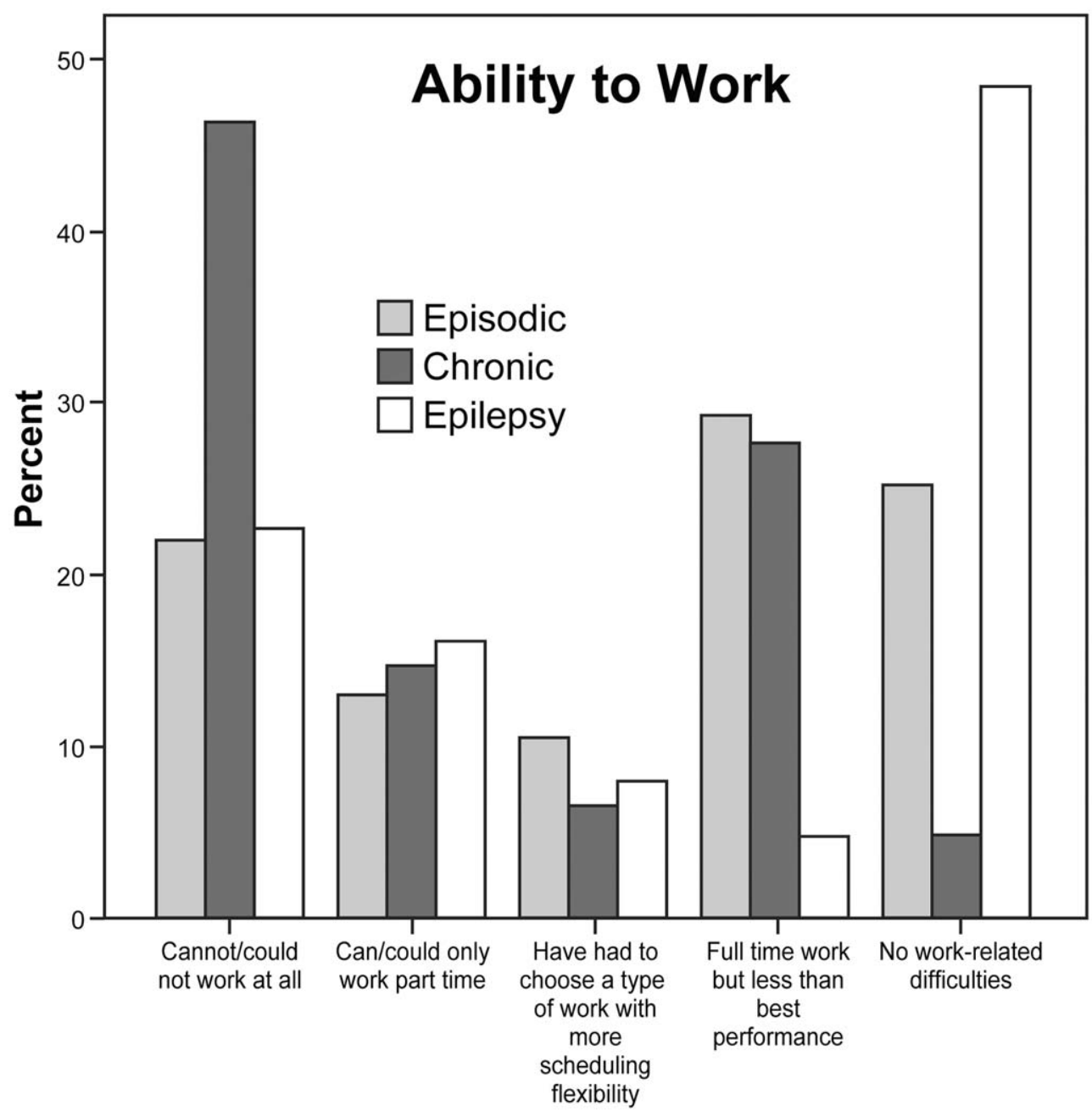

Figure 1. Effect on Work. Results of questionnaire in which subjects were asked about whether they could work. If they were not working and not trying to work they were asked to imagine trying to work with their current headache or epilepsy condition. Chronic migraine had worse ability to function.

doi:10.1371/journal.pone.0054074.g001 


\section{Effect of Migraine on Need to Rest}

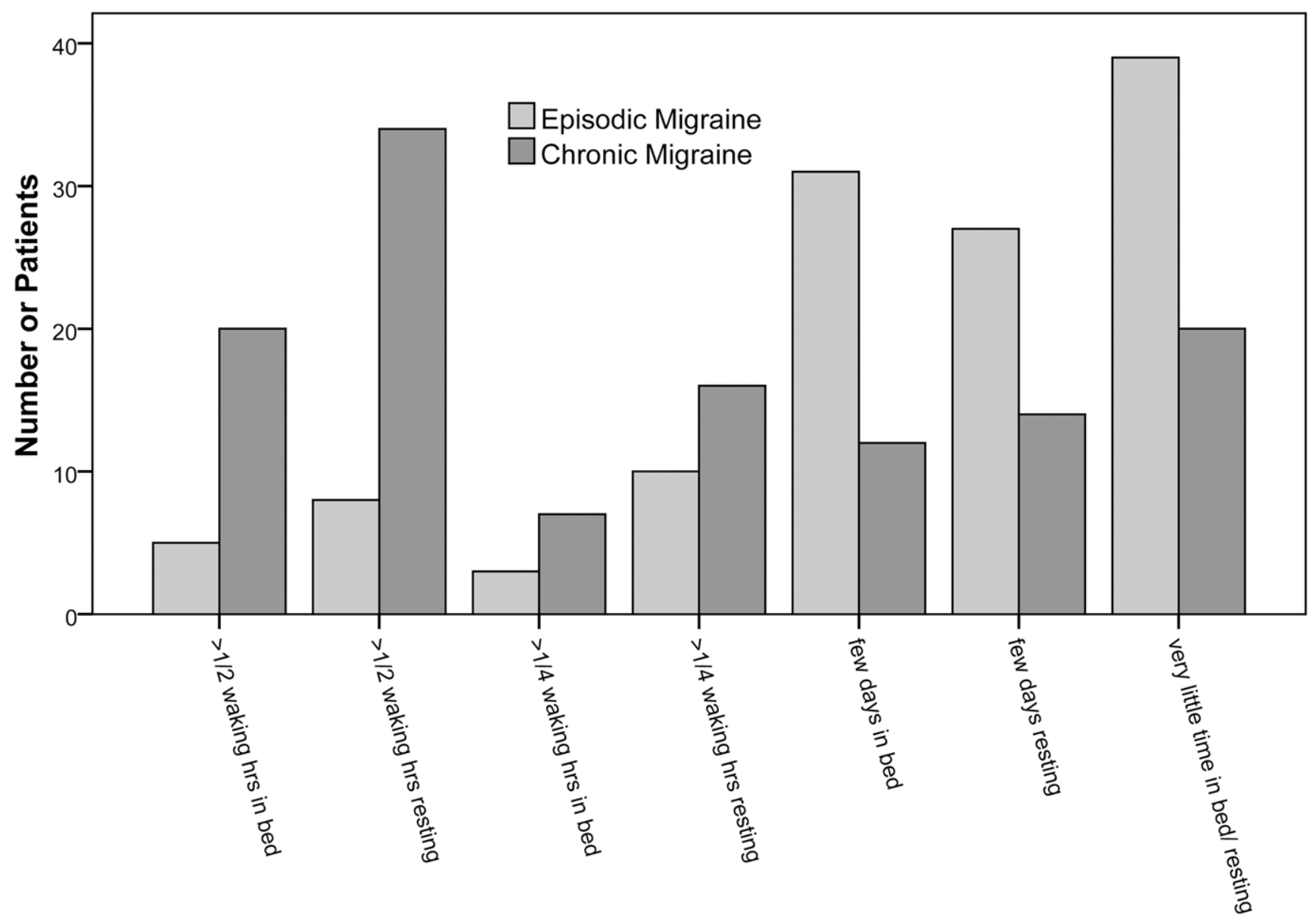

Figure 2. Effect on Need to Rest. Distribution of answers to questionnaire on the effect of migraine on need to rest and spending time in bed. Subjects with chronic migraine reported spending more time in bed and resting $(p<0.001$, Krushal-Wallis test). doi:10.1371/journal.pone.0054074.g002

\section{The Liverpool Impact of Epilepsy Scale}

This scale is a 9-item component of the extensive Liverpool Seizure Severity Scale that assesses patients' perception of the impact of epilepsy on work, activity, personal relationships, and self-image.

\section{Ability to Work Score}

Subjects were asked about the impact migraine or epilepsy had on their ability to work (and to assume they were trying to work if they were homemakers, retired, or had given up trying to work) using five ranked questions (the lowest level of function was chosen if multiple responses were given) (Figure 1).

\section{Need to Rest Score}

Subjects with migraine were asked about their need to lie down or rest. They were given seven possible answers (Figure 2) that were ranked with the lowest level of function if multiple responses were given.

\section{Statistical Considerations}

To detect a difference of 10 points in the SSCI score between the more and less disabled halves of the EM and CM patients at a 0.05 significance level, assuming a standard deviation of 19.7 (based on previous data), a sample size of 62 was required [13]. Thus, 124 subjects were required for each group. To distinguish a 10-point difference in mean scores between Ep and CM patients, a sample of 62 patients would be sufficient. Data were analyzed using SPSS. Pearson correlations were used unless otherwise specified.

\section{Results}

One hundred twenty-four EM and CM and 62 Ep patients completed the study. One subject in each migraine group was excluded due to incomplete data, other than income. Internal consistency for the four scales, as assessed by Cronbach's alpha, achieved good levels. The coefficients for the four scales were 0.96, 0.74, 0.86, and 0.83 for SSCI, MIDAS, Liverpool Impact Scale, and SF-12, respectively.

A higher percentage of EM and CM than Ep patients were female. EM patients were slightly older and had more education and higher incomes (Table 1). CM patients had more work-related disability (or potential disability) than EM patients and Ep patients $(\mathrm{p}<0.001 \mathrm{EM}$ vs CM, and Ep vs CM, p = NS EM vs Ep MannWhitney) (Figure 1). Headache severity was similar in migraine patients (Table 2). Patients with CM had greater need to rest than patients with EM (Figure 2). Of the 62 epilepsy patients, 21 
Table 1. Basic Demographics.

\begin{tabular}{|c|c|c|c|c|c|c|c|}
\hline & $\begin{array}{l}\text { Episodic } \\
\text { Migraine } \\
(E M) \\
(n=123)\end{array}$ & $\begin{array}{l}\text { Chronic } \\
\text { Migraine } \\
\text { (CM) } \\
(n=123)\end{array}$ & $\begin{array}{l}\text { Epilepsy } \\
\text { (Ep) } \\
N=62\end{array}$ & p Value & $\begin{array}{l}\text { CM/EM } \\
\mathbf{p}\end{array}$ & $\begin{array}{l}\text { EM/Ep } \\
P\end{array}$ & $\begin{array}{l}\text { CM/Ep } \\
P\end{array}$ \\
\hline Age & $44.7 \pm 12.5$ & $40.9 \pm 12.2$ & $38.4 \pm 13.1$ & $0.003^{*}$ & $0.054^{* *}$ & $0.054^{* *}$ & $0.004^{* *}$ \\
\hline Gender & & & & & $\mathrm{NS}^{\circ}$ & $<0.001^{\circ}$ & $<0.001^{\circ}$ \\
\hline Male & $17.1 \%$ & $15.4 \%$ & $45.2 \%$ & & & & \\
\hline Female & $82.9 \%$ & $84.6 \%$ & $59.8 \%$ & & & & \\
\hline Race & & & & $0.028 \dagger$ & $0.036+1$ & $0.008+1$ & NSt广 \\
\hline Caucasian & $95.1 \%$ & $87.8 \%$ & $83.9 \%$ & & & & \\
\hline African-American & $4.1 \%$ & $7.3 \%$ & $6.5 \%$ & & & & \\
\hline Other & $0.8 \%$ & $4.9 \%$ & $6.5 \%$ & & & & \\
\hline Education & & & & $<0.001 \uparrow$ & $0.015+\dagger$ & $<0.001 \uparrow \dagger$ & $0.009 \dagger \dagger$ \\
\hline High school & $15.4 \%$ & $17 \%$ & $35.5 \%$ & & & & \\
\hline Some college & $12.2 \%$ & $24.4 \%$ & $21.0 \%$ & & & & \\
\hline Associates & $5.7 \%$ & $8.9 \%$ & $11.3 \%$ & & & & \\
\hline Bachelors & $31.7 \%$ & $26.8 \%$ & $17.7 \%$ & & & & \\
\hline Graduate/Professional & $35.0 \%$ & $22.8 \%$ & $14.5 \%$ & & & & \\
\hline Household Income & & & & $<0.001 \dagger$ & $<0.001 \dagger$ & $<0.001 \uparrow \dagger$ & $0.21+1$ \\
\hline $0-18.5000$ & $5.7 \%$ & $13.8 \%$ & $21.0 \%$ & & & & \\
\hline $18,5005-35000$ & $8.9 \%$ & $11.4 \%$ & $19.4 \%$ & & & & \\
\hline $35,000-55,000$ & $9.8 \%$ & $21.1 \%$ & $14.5 \%$ & & & & \\
\hline $55,000-90,000$ & $28.5 \%$ & $31.7 \%$ & $14.5 \%$ & & & & \\
\hline$>90,000$ & $46.3 \%$ & $20.3 \%$ & $24.2 \%$ & & & & \\
\hline $\mathrm{N}$ & 122 & 121 & 58 & & & & \\
\hline \multicolumn{8}{|c|}{$\begin{array}{l}{ }^{*}=\text { ANOVA; } \\
{ }^{* *} \text { multiple comparisons with Bonferroni adjustment. } \\
{ }^{\circ}=\text { Chi Square test. } \\
+=\text { Kruskal-Wallis; } \\
{ }^{\dagger}=\text { Mann-Whitney. } \\
\text { doi:10.1371/journal.pone. } 0054074 . t 001\end{array}$} \\
\hline
\end{tabular}

patients $(33.9 \%)$ had a history of surgery (i.e., temporal lobectomy or resection of the seizure foci), two patients $(3.2 \%)$ had a history of both surgery and vagus nerve stimulator insertion, one patient $(1.6 \%)$ had a history of vagus nerve stimulator insertion, and 38 patients $(61.3 \%)$ did not have any history of surgery or vagus nerve stimulation. Epilepsy was focal in 49 patients (79\%), generalized in nine $(14.5 \%)$ and unspecified in four $(6.5 \%)$. Forty-eight patients $(77.4 \%)$ did not report any generalized tonic-clonic seizures in the past month, while 12 patients (19.4\%) did. One-year seizure frequencies (which included all types of seizures) were divided into three groups; 25 patients were seizure-free (40.3\%), 25 patients $(40.3 \%)$ had less than four seizures, and $10(16.1 \%)$ patients had more than four seizures.

CM patients experienced statistically significantly more stigma than EM or Ep patients as measured by SSCI scores (Figure 3, Table 2). We examined the ratio of internalized stigma to the total stigma score, SSCI-I/SSCI, and found that a higher proportion of the stigma reported by CM and EM patients could be attributed to internalized stigma than enacted stigma (Table 2). The ratio of SSCI-I to SSCI (total) did not vary by age or gender, but correlated negatively with ability to work $(\mathrm{r}=-0.201, \mathrm{p}<0.001)$. Functional and quality-of-life measurements were lower for CM than EM (Table 2). SF-12 scores were lower for CM than EM or Ep patients, and lower for EM than Ep patients on the physical component subscale (PCS) but not the mental component subscale (MCS) (Table 2)

\section{Correlations}

SSCI, SSCI-I, and SSCI-E were strongly correlated (SSCI with SSCI-E, and SSCI-I; $r=0.904$, and 0.963, and for SSCI-E with SSCI-I $r=0.755, \mathrm{p}<0.001$ for all) and with similar correlations for each disease group. In general, correlations for SSCI, SSCI-I, and SSCI-E were similar. Therefore, we will present only correlations with SSCI and indicate areas where results differed between SSCII and SSCI-E (Table 3).

All three groups demonstrated no association of gender or race on SSCI, although the groups were heavily white. Migraine groups showed no effect of age, education, or income on SSCI. With epilepsy only, SSCI correlated positively with age $(r=0.347$, $\mathrm{p}=0.006$ ) and negatively with education (Spearman's $r=-0.346$, $\mathrm{p}=0.008)$ and income $(\mathrm{r}=-0.336, \mathrm{p}=-0.008)$. All groups had a strong negative correlation between ability to work and SSCI $(\mathrm{r}=-0.511(\mathrm{EM}), \mathrm{r}=-0.497(\mathrm{CM}), \mathrm{r}=-0.475(\mathrm{Ep}), \mathrm{p}<0.001$ for all). SSCI was negatively correlated with PCS $(r=-0.179$ $\mathrm{p}=0.047(\mathrm{EM}), \mathrm{r}=-0.429 \mathrm{p}<0.001 \quad(\mathrm{CM})$, and $\mathrm{r}=-0.472$ $\mathrm{p}<0.001(\mathrm{Ep}))$ and MCS $(\mathrm{r}=-0.592 \mathrm{p}<0.001 \quad(\mathrm{EM})$, $\mathrm{r}=-0.575 \mathrm{p}<0.001(\mathrm{GM})$ and $\mathrm{r}=-0.581 \mathrm{p}<0.001(\mathrm{Ep}))$. Only for EM did the SSCI-E not correlate with PCS (Table 3). In migraine, disability (MIDAS) was correlated with SSCI for EM 
Table 2. Measurements of Stigma, Quality of Life, and Impact.

\begin{tabular}{|c|c|c|c|c|c|c|c|}
\hline & $\begin{array}{l}\text { Episodic } \\
\text { Migraine }\end{array}$ & $\begin{array}{l}\text { Chronic } \\
\text { Migraine }\end{array}$ & Epilepsy & $\mathbf{p}^{*}$ value & $\begin{array}{l}\text { CM/EM } \\
\mathbf{p}\end{array}$ & $\begin{array}{l}\text { CM/Ep } \\
\mathbf{p}\end{array}$ & $\begin{array}{l}\text { EM/Ep } \\
p\end{array}$ \\
\hline Total SSCI score & $\begin{array}{l}41.7 \pm 14.8 \\
\text { (Median: } 36 \text { ) }\end{array}$ & $\begin{array}{l}54.0 \pm 20.2 \\
\text { (Median: } 53 \text { ) }\end{array}$ & $\begin{array}{l}44.6 \pm 16.3 \\
\text { (Median: } 42.5 \text { ) }\end{array}$ & $<0.001^{*}$ & $<0.001$ & 0.002 & NS \\
\hline SSCl -I & $\begin{array}{l}26.1 \pm 10.0 \\
\text { (Median: } 24 \text { ) }\end{array}$ & $\begin{array}{l}34.5 \pm 12.9 \\
\text { (Median: } 33 \text { ) }\end{array}$ & $\begin{array}{l}26.7 \pm 9.7 \\
\text { (Median: } 28)\end{array}$ & $<0.001^{*}$ & $<0.001$ & $<0.001$ & NS \\
\hline $\mathrm{SSCl}-\mathrm{E}$ & $\begin{array}{l}14.9 \pm 5.8 \\
\text { (Median: 13) }\end{array}$ & $\begin{array}{l}19.5 \pm 8.3 \\
\text { (Median: 17) }\end{array}$ & $\begin{array}{l}18.0 \pm 8.1 \\
\text { (Median: } 14 \text { ) }\end{array}$ & $<0.001^{*}$ & $<0.001$ & $<0.001$ & NS \\
\hline SSCI-I/SSCI Total & $0.622 \pm 0.003$ & $0.637 \pm 0.004$ & $0.598 \pm 0.005$ & $<0.001$ & NS & $<0.001$ & 0.049 \\
\hline \multicolumn{8}{|l|}{ SF-12 } \\
\hline PCS & $\begin{array}{l}42.31 \pm 8.5 \\
\text { (Median: } 43 \text { ) }\end{array}$ & $\begin{array}{l}37.1 \pm 8.1 \\
\text { (Median: 37) }\end{array}$ & $\begin{array}{l}47.6 \pm 9.4 \\
\text { (Median: } 51 \text { ) }\end{array}$ & $<0.001^{*}$ & $<0.001$ & $<0.001$ & $<0.001$ \\
\hline MCS & $\begin{array}{l}47.61 \pm 10.2 \\
\text { (Median: } 49 \text { ) }\end{array}$ & $\begin{array}{l}39.4 \pm 11.8 \\
\text { (Median: } 37 \text { ) }\end{array}$ & $\begin{array}{l}46.6 \pm 11.9 \\
\text { (Median: } 48 \text { ) }\end{array}$ & $<0.001^{*}$ & $<0.001$ & $<0.001$ & NS \\
\hline Total MIDAS score & $\begin{array}{l}28.54 \pm 38.7 \\
\text { (Median: 19) }\end{array}$ & $\begin{array}{l}86.5 \pm 77.86 \\
\text { (Median: 60) }\end{array}$ & & & $<0.001 \uparrow$ & & \\
\hline Headache frequency (per 90 days) & $\begin{array}{l}18.7 \pm 13.3 \\
\text { (Median: } 16)\end{array}$ & $\begin{array}{l}55.2 \pm 29.1 \\
\text { (Median: } 60 \text { ) }\end{array}$ & & & $<0.001 \uparrow$ & & \\
\hline Severity (0-10 scale) & $\begin{array}{l}6.1 \pm 3.6 \\
\text { (Median: 6.0) }\end{array}$ & $\begin{array}{l}6.3 \pm 1.4 \\
\text { (Median: 6.0) }\end{array}$ & & & $0.085 \dagger$ & & \\
\hline Liverpool Impact & & & $\begin{array}{l}9.2 \pm 6.8 \\
\text { (Median: 8) }\end{array}$ & & & & \\
\hline
\end{tabular}

*ANOVA, Bonferroni correction for multiple comparisons;

'Mann-Whitney. Headache severity and frequency based on MIDAS questions 6 and 7.

Abbreviations: $\mathrm{SCCl}=$ stigma scale for chronic illness; SSCI-I = internalized stigma; $\mathrm{SSCl}-\mathrm{E}=$ enacted stigma; $\mathrm{SF}-12=$ short form 12 in the medical outcomes study Quality of Life questionnaire; PCS = physical component subscale of SF-12; MCS = mental component subscale of SF-12; MIDAS=migraine disability scale; Liverpool impact scale $=$ component of the Liverpool seizure severity scale.

doi:10.1371/journal.pone.0054074.t002

$(\mathrm{r}=0.445)$ and for CM $(0.405, \mathrm{p}<0.001$ for both). In Ep, impact score correlated with SSCI Score $(r=0.527, \mathrm{p}<0.001)$. MIDAS and ability to work were only modestly correlated $(r=-0.366$ for $\mathrm{EM}, \mathrm{r}=-0.368$ for CM, $\mathrm{p}<0.001$ for both), indicating substantial differences in what these variables measured.

In migraine, SSGI had a moderate negative correlation with need to rest (Spearman's $r=0.479, \mathrm{p}<0.001(\mathrm{EM}) 0.400, \mathrm{p}<0.001$ $(\mathrm{CM}))$. SSCI correlated with headache severity for $\mathrm{EM}(\mathrm{r}=0.205$, $\mathrm{p}=0.023)$ and $\mathrm{CM}(\mathrm{r}=0.218, \mathrm{p}=0.015)$. SSCI-E did not correlate with severity for $\operatorname{EM~}(r=0.033, p=N S)$, but did for $\mathrm{CM}$ $(\mathrm{r}=0.211, \mathrm{p}=0.019)$. Migraine frequency did not correlate with SSCI for EM $(r=0.086, p=N S)$ but did for CM $(r=0.218$, $\mathrm{p}=0.015)$.

\section{Analysis of Covariance (ANCOVA)}

A 2 (Gender) X 3 (Group: EM, CM, and Ep) ANCOVA was conducted. The dependent variable was the SSCI score and the covariates were: (a) age, (b) income, (c) ability to work, (d) physical component score (SF12), and (e) education. Preliminary analyses evaluating the homogeneity-of-slopes assumption indicated that the relationships between the covariates and the dependent variable did not differ significantly. Results indicated no statistically significant interaction effect or gender effect; however, there was a significant group effect: $\mathrm{F}(2,290)=3.17, \mathrm{p}=.043$, $\eta^{2}=.021$. Follow-up tests were conducted to evaluate pairwise differences among these adjusted means. Based on the least significant difference procedure, the adjusted mean for EM (43.7; $95 \%$ confidence interval, 40.9 to 46.6 ) differed significantly from both CM (49.3; 95\% confidence interval, 46.2 to 52.4) and Ep (46.5; 95\% confidence interval, 41.6 to 51.6). There were no significant differences between CM and Ep. Ability to work achieved a strong association with SSCI as measured by the $\eta^{2}$ of.157. The only other significant covariant was PCS with a weak $\eta^{2}$ of.024.

\section{Discussion}

In this study we used the SSCI, a newly developed questionnaire to assess stigma in multiple neurological illnesses. The SSCI was developed as one element of a multiple site project to produce relevant and psychometrically robust quality of life assessment tools for adults and children. The SSCI is one of 13 tools resulting from this project and is available as a 24-item questionnaire, as well as an 8-item short form, which was not yet available when the study was conducted. The 24-item scale has two subscales, "internalized" and "enacted". Stigma scores for Ep and EM were consonant with those found in a panel of diverse neurological patients whose SSCI scores averaged 42.7 (+/-19.7). CM patients reported much higher SSCI scores than either group (54.0+/ -20.2). CM patients reported particularly high SSCI-I scores, which suggests that, of the three groups, they are the most likely to identify with the stereotypes and negative labels that attach to migraine.

Our finding that CM patients reported more stigma than both epilepsy patients and patients with EM contradicts that of Aydemir et. al, who found that epilepsy patients felt more stigmatized than migraine patients in a clinical sample in Turkey [10]. Methodological differences may explain these divergent findings. Aydemir et. al did not differentiate between CM and EM, which, according to our analysis, could affect stigma scores. In addition, they used a three-item stigma scale that had not been validated for use across disease groups. Finally, stigma is a process deeply embedded in 


\section{Histogram of Stigma Scores}
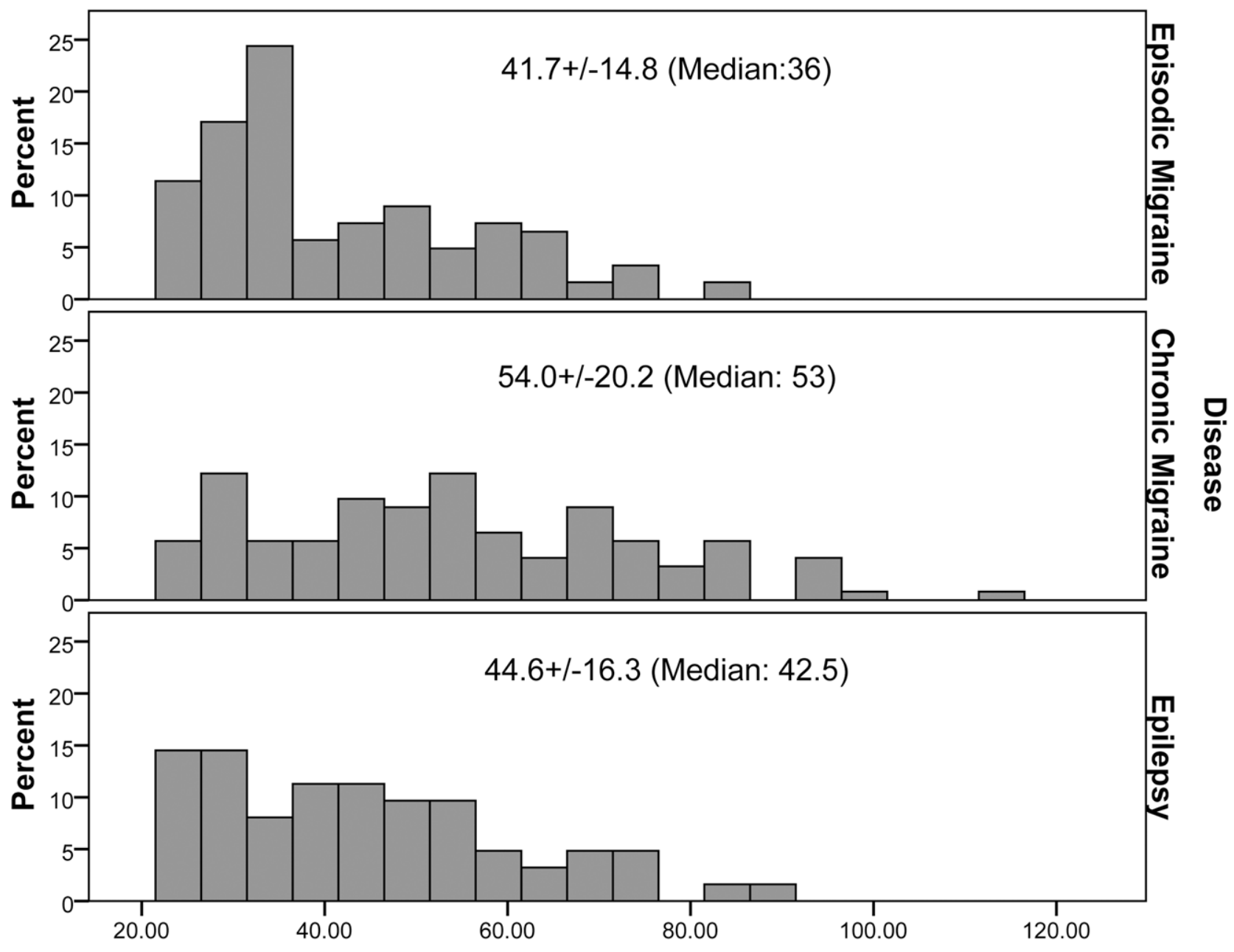

Total SSCI Score

Figure 3. Stigma Scores. Distribution of stigma scores for EM, CM, and Ep. Scores for CM are significantly higher than for EM or Ep. CM scores were higher than SSCl scores of $42.7+/-19.7$ for an internet panel of diverse neurological patients used to validate the SSCI ( $p<0.001$, z-test), while EM and Ep were not.

doi:10.1371/journal.pone.0054074.g003

social and cultural norms, and stigma might attach differently to epilepsy and migraine in Turkey than in the United States.

We observed a numerically greater SSCI-I than SSCI-E for the migraine groups, so we created an exploratory variable, SSCI-I/ Total SSCI to assess internalized stigma as a proportion of the overall stigma score. Although the mean ratio of each group differed only slightly, the standard deviation was small and the difference reached significance. Both CM and EM report higher rates of internalized stigma as a proportion of their overall stigma score than Ep. This suggests that migraine patients have a more vigorous process of converting enacted stigma into internalized stigma. Alternatively, migraine patients may be better able to suppress enacted stigma by being more circumspect about divulging their medical condition while experiencing the internalized stigma commensurate with their illness severity [15].

Migraine patients reported equally high stigma scores across age, income, and education. In contrast, for epilepsy patients, younger age, higher education, and higher income correlated with lower SSCI scores. This finding suggests that a cultural shift may be underway and that education and anti-stigma efforts in epilepsy are taking hold. Anti-stigma efforts have been more limited for migraine.

Patients' reports of the impact of their disease correlated with SSCI scores for both migraine (as measured by MIDAS, ability to work and need to rest) and epilepsy (as measured by the Liverpool impact scale). The only exception to this was pain severity, which correlated with SSCI for CM, but not for SSCI-E in EM. This may indicate more reserve among patients with EM to handle more severe headache pain, or it may suggest that experiencing intermittent, severe head pain, as people with EM do, is less stigmatizing, since it is more consistent with public perception of normal migraine.

The mental component of the SF-12 was more highly correlated with stigma than the physical component. In our analysis, we elected to model the physical component score of the SF-12 as an independent variable as it seems implausible that the physical consequences of migraine or epilepsy were caused by stigma. A more difficult choice was to view the MCS as an independent 
Table 3. Correlations Between Scales.

\begin{tabular}{|c|c|c|c|c|c|c|c|c|c|c|}
\hline \multicolumn{3}{|l|}{ Migraine Type } & \multirow{2}{*}{$\begin{array}{l}\text { SSCI-I } \\
.965\end{array}$} & \multirow{2}{*}{$\begin{array}{l}\text { SSCI-E } \\
.889\end{array}$} & \multirow{2}{*}{$\begin{array}{l}\begin{array}{l}\text { Ability } \\
\text { to work }\end{array} \\
-.511\end{array}$} & \multirow{2}{*}{$\begin{array}{l}\text { PCS12 } \\
-.179\end{array}$} & \multirow{2}{*}{$\begin{array}{c}\text { MCS12 } \\
-.592\end{array}$} & \multirow{2}{*}{$\begin{array}{l}\begin{array}{l}\text { Total } \\
\text { MIDAS }\end{array} \\
.445\end{array}$} & \multirow{2}{*}{$\begin{array}{l}\begin{array}{l}\text { Need } \\
\text { to rest }\end{array} \\
-.464\end{array}$} & \multirow[t]{2}{*}{$\begin{array}{l}\text { Total } \\
\text { Impact }\end{array}$} \\
\hline Episodic $(N=123)$ A & Total SSCI & $\mathrm{p}$-value & & & & & & & & \\
\hline & & Sig. (2-tailed) & .000 & .000 & .000 & .047 & .000 & .000 & .000 & \\
\hline & $\mathrm{SSCl}$ int & $p$-value & & .738 & -.531 & -.198 & -.636 & .471 & -.498 & \\
\hline & & Sig. (2-tailed) & & .000 & .000 & .028 & .000 & .000 & .000 & \\
\hline & $\mathrm{SSCl}$ enact & $\mathrm{p}$-value & & & -.389 & -.116 & -.415 & .324 & -.324 & \\
\hline & & Sig. (2-tailed) & & & .000 & .202 & .000 & .000 & .000 & \\
\hline & Ability to work & $p$-value & & & & .336 & .328 & -.366 & .490 & \\
\hline & & Sig. (2-tailed) & & & & .000 & .000 & .000 & .000 & \\
\hline & PCS12 & $\mathrm{p}$-value & & & & & -.018 & -.258 & .281 & \\
\hline & & Sig. (2-tailed) & & & & & .845 & .004 & .002 & \\
\hline & MCS12 & $p$-value & & & & & & -.497 & .427 & \\
\hline & & Sig. (2-tailed) & & & & & & .000 & .000 & \\
\hline & Total MIDAS & $\mathrm{p}$-value & & & & & & & -.407 & \\
\hline & & Sig. (2-tailed) & & & & & & & .000 & \\
\hline & Need to rest & $\mathrm{p}$-value & & & & & & & & \\
\hline & & Sig. (2-tailed) & & & & & & & & \\
\hline \multirow[t]{16}{*}{ Chronic $(N=123)$ B } & Total SSCI & $\mathrm{p}$-value & .968 & .919 & -.497 & -.429 & -.575 & .405 & -.429 & \\
\hline & & Sig. (2-tailed) & .000 & .000 & .000 & .000 & .000 & .000 & .000 & \\
\hline & SSCl int & $\mathrm{p}$-value & & .789 & -.511 & -.412 & -.616 & .433 & -.449 & \\
\hline & & Sig. (2-tailed) & & .000 & .000 & .000 & .000 & .000 & .000 & \\
\hline & $\mathrm{SSCl}$ enact & $\mathrm{p}$-value & & & -.408 & -.398 & -.434 & .308 & -.340 & \\
\hline & & Sig. (2-tailed) & & & .000 & .000 & .000 & .001 & .000 & \\
\hline & Ability to work & $\mathrm{p}$-value & & & & .469 & .321 & -.368 & .577 & \\
\hline & & Sig. (2-tailed) & & & & .000 & .000 & .000 & .000 & \\
\hline & PCS12 & $p$-value & & & & & .022 & -.349 & .349 & \\
\hline & & Sig. (2-tailed) & & & & & .808 & .000 & .000 & \\
\hline & MCS12 & $\mathrm{p}$-value & & & & & & -.332 & .430 & \\
\hline & & Sig. (2-tailed) & & & & & & .000 & .000 & \\
\hline & Total MIDAS & $p$-value & & & & & & & -.548 & \\
\hline & & Sig. (2-tailed) & & & & & & & .000 & \\
\hline & Need to rest & $p$-value & & & & & & & & \\
\hline & & Sig. (2-tailed) & & & & & & & & \\
\hline \multirow[t]{16}{*}{ Epilepsy $(N=62) C$} & Total SSCI & $\mathrm{p}$-value & .932 & .901 & -.475 & -.472 & -.581 & & & .527 \\
\hline & & Sig. (2-tailed) & .000 & .000 & .000 & .000 & .000 & & & .000 \\
\hline & SSCI int & $p$-value & & .684 & & & & & & .530 \\
\hline & & Sig. (2-tailed) & & .000 & -.461 & -.443 & -.594 & & & .000 \\
\hline & SSCI enact & $\mathrm{p}$-value & & & -.407 & -.423 & -.461 & & & .428 \\
\hline & & Sig. (2-tailed) & & & .001 & .001 & .000 & & & .001 \\
\hline & Ability to work & $\mathrm{p}$-value & & & & .521 & .362 & & & -.452 \\
\hline & & Sig. (2-tailed) & & & & .000 & .004 & & & .000 \\
\hline & PCS12 & $p$-value & & & & & .444 & & & -.533 \\
\hline & & Sig. (2-tailed) & & & & & .000 & & & .000 \\
\hline & MCS12 & $p$-value & & & & & & & & -.740 \\
\hline & & Sig. (2-tailed) & & & & & & & & .000 \\
\hline & Total MIDAS & $\mathrm{p}$-value & & & & & & & & \\
\hline & & Sig. (2-tailed) & & & & & & & & \\
\hline & Need to rest & $p$-value & & & & & & & & \\
\hline & & Sig. (2-tailed) & & & & & & & & \\
\hline
\end{tabular}

2-tailed Pearson correlation coefficients for variables associated with episodic (A) and chronic (B) migraine, and for epilepsy (C). The p-values are not adjusted for multiple comparisons.

Abbreviations: $\mathrm{SCCl}=$ stigma scale for chronic illness; $\mathrm{SSCI}-\mathrm{I}=$ internalized stigma; $\mathrm{SSCl}-\mathrm{E}=$ enacted stigma; $\mathrm{PCS}=$ physical component subscale of SF-12; $\mathrm{MCS}=$ mental component subscale of SF-12; MIDAS = migraine disability scale.

doi:10.1371/journal.pone.0054074.t003 
variable and exclude it from the analysis. This is consistent with the proposition that the stigma itself causes the MCS change, and seems more plausible than higher MCS causing stigma. This assumption should be viewed with some skepticism as an increased MCS as a result of migraine or its comorbidities could result in increased stigma and elevation of the SSCI score.

In our model, once we accounted for all factors, CM and Ep had similar stigma while EM had less. In other words, CM incurs more stigma than Ep, but only because in our sample people with CM experience more disability and are less able to work. However, CM incurs more stigma than EM, even when all factors are taken into account, perhaps because EM aligns best with public perceptions of the disease. Although we were able to find significant correlations, we were only able to account for a modest amount of the variance, indicating that other factors not considered here, including individual factors, such as resilience, are likely important determinants of an individual's experience of stigma.

The study has several strengths. It is the largest study of stigma in migraine; the first study of stigma in migraine that uses validated scales, including the SSCI; and the first study of stigma in migraine in the United States. In this case, the reliance on physician diagnosis and chart notes for diagnosis is likely to be more accurate than cross-sectional diagnostic interviews.

However, this study has several weaknesses. Generalizability may be limited, as patients in this study were drawn from highly specialized clinics. Also, many EM patients at the headache clinic are likely to have had CM in the past, which would reduce differences between groups. We did not differentiate between types of epilepsy or account for the presence of migraine aura. We

\section{References}

1. Goffman E (1963) Stigma: notes on the management of spoiled identity. New York: Simon and Schuster.

2. Genberg BL, Hlavka Z, Konda KA, Maman S, Charivalertsak S, et al. (2009) A comparison of HIV/AIDS-related stigma in four countries: negative attitudes and perceived acts of discrimination towards people living with HIV/AIDS. Soc Sci Med 68: 2279-2287.

3. Koller M, Kussman J, Lorenz W, Jenkins M, Voss M, et al. (1996) Symptom reporting in cancer patients: the role of negative affect and experienced social stigma. Cancer 77: 983-995.

4. Link BG, Phelan JC (2001) Conceptualizing stigma. Ann Rev Sociol 27: 363385

5. Walton GM, Cohen GL (2011) A brief social-belonging intervention improves academic and health outcomes of minority students. Science 331: 1447-1451.

6. Link BG, Phelan JC (2006) Stigma and its public health implications. Lancet 367: 528-529.

7. Bandstra NF, Camfield CS, Camfield PR (2008) Stigma of epilepsy. Can J Neurol Sci 35: 436-440

8. Scambler G (2004) Reframing stigma: felt and enacted stigma and challenges to the sociology of chronic and disabling conditions. Social Theory and Health 2: $29-46$. lacked a validated "ability to work" scale that would apply to both migraine and epilepsy, and would account for people who are homemakers or have stopped trying to work. Our disability and impact scales overlap in what they measure, however the correlations between these scales were modest, indicating diversity in what they measured. Other interesting data, such as duration of illness, psychiatric co-morbidity, number of medications, and body mass index, were not collected.

Stigma has important public health implications that ought to be addressed [6]. As in epilepsy, we should undertake to reduce the stigma of migraine. These interventions may take place at multiple levels: by endeavoring to reduce stigma among the public through education, advocacy, and legal and policy interventions; at the organizational level, through training programs for clinicians; and at the intrapersonal level, through counseling, therapy, support, and empowerment programs [16].

\section{Acknowledgments}

The authors thank Anthony J. Guarino, PhD for his statistical expertise, Sharon Bzostek, PhD for her astute comments, and Dr. Michael R. Sperling and other physicians at the Jefferson Epilepsy Center at Thomas Jefferson University Hospital for kindly providing access to their patients.

\section{Author Contributions}

Revised manuscript for intellectual content: WBY JK. Final approval of completed manuscript: WBY JEP IXT JK. Conceived and designed the experiments: WBY JEP JK. Performed the experiments: JEP IXT. Analyzed the data: WBY JK. Wrote the paper: WBY JK.

9. Finch BK, Kolody B, Vega WA (2000) Perceived discrimination and depression among Mexican-origin adults in California. J Health Soc Behav 41: 295-313.

10. Aydemir N, Ozkara C, Unsal P, Canbeyli R (2011) A comparative study of health related quality of life, psychological well-being, impact of illness and stigma in epilepsy and migraine. Seizure 20: 679-685.

11. Jacoby A (2008) Epilepsy and stigma: an update and critical review. Curr Neurol Neurosci Rep 8: 339-344.

12. Headache Classification Subcommittee of the International Headache Society (2004) The international classificaation of headache disorders. 2nd edition. Cephalalgia 24: 1-160.

13. Rao D, Choi SW, Victorson D, Bode R, Peterman A, et al. (2009) Measuring stigma across neurological conditions: the development of the stigma scale for chronic illness (SSCI). Qual Life Res 18: 585-595.

14. Cella D, Lai JS, Nowinski CJ, Victorson D, Peterman A, et al. (2012) NeuroOOL: Brief measures of health-related quality of life for clinical research in neurology. Neurology 78: 1860-1867.

15. Jacoby A (1994) Felt versus enacted stigma: a concept revisited. Evidence from a study of people with epilepsy in remission. Soc Sci Med 38: 269-274.

16. Heijnders M, Van Der Meij S (2006) The fight against stigma: an overview of stigma-reduction strategies and interventions. Psychol Health Med 11: 353-363. 